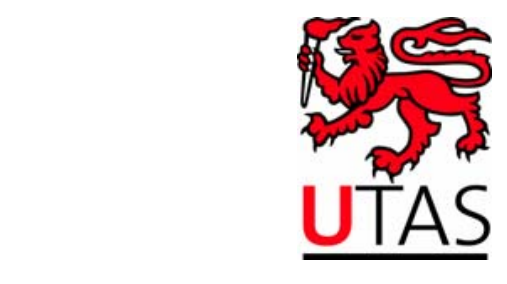

SCHOOL OF ECONOMICS AND FINANCE

Discussion Paper 2007-07

The Term Spread and GDP Growth in Australia

\author{
Jacob Poke and Graeme Wells
}

ISSN 1443-8593

ISBN 978-1-86295-432-8 


\title{
The Term Spread and GDP Growth in Australia
}

\author{
Jacob Poke \\ Graeme Wells* \\ Goldman Sachs JB Were \\ University of Tasmania \\ and CAMA
}

Revised November 162007

\begin{abstract}
This paper analyses the effectiveness of the spread between short and long term interest rates for predicting GDP growth in Australia, and whether the predictive relation deteriorates, as theory suggests, with the adoption of a credible inflation-targeting regime. We test whether predictive power is sensitive to inclusion of other conditioning variables which may be useful in forecasting GDP growth, and whether forecasting significance is due primarily to the expected change in short-term interest rates, the term premium, or a combination of the two. In a simple bivariate model, results strongly suggest that the shift to a credible inflationtargeting regime has reduced the predictive content of the term spread. However, extensions to this basic model tend to undermine this result. The predictive power of the term spread in Australia may have been oversold.
\end{abstract}

\footnotetext{
*Paper to be presented at RBA Workshop on Monetary Policy in Open Economies, December 2007. We acknowledge helpful comments from Arusha Cooray, Mardi Dungey and seminar participants at the University of Tasmania. JEL classification: E32, E43, E47, E52. UTAS Eprint Nos. 340203, 340208, 340401. Correspondence: Graeme Wells, School of Economics and Finance, University of Tasmania, Private Bag 85, Hobart, Australia 7005. email: graeme.wells@utas.edu.au
} 


\section{Introduction}

The use of financial-market data to predict economic activity has a long history. Tobin's ' $q$ theory' for investment, for example, is based on the idea that if stock-market valuation of the capital stock is greater than its replacement value, firms have an incentive to invest. So changes in $q$ should help predict changes in capital formation. Alternatively, a consumption capital asset pricing model $(\mathrm{CAPM})$ predicts that a change in the real interest rate changes the relation between present and future real consumption as households reallocate consumption across time. Changes in the real interest rate should help forecast changes in consumption. To give a third example, changes in the 'term spread' - the difference between nominal yields on long and short-term risk-free securities - have been postulated to forecast changes in inflation and real output. As pointed out by Ang, Piazzesi and Wei (2006), every US recession after the mid-1960's was predicted by a negative-sloping yield curve, which was observed within 6 quarters of the impending recession. More general linkages between asset prices, output and inflation were recently surveyed by Stock and Watson (2003). They conclude that 'there is evidence that the term spread is a serious candidate as a predictor of output growth and recessions. The stability of this proposition in the United States is questionable, however, and its universality is unresolved' (p.801).

Our objective is to investigate the predictive power of the term spread for real GDP growth in Australia. In addition to providing an update to Australian work completed a decade ago, our analysis is innovative in two main ways. We study the stability of the relation across successive monetary policy regimes - denoted the 'Checklist' and 'Targeting' regimes in what follows - since, as is outlined in the following section, there is a number of arguments as to why adoption of a credible inflation-targeting regime is likely to break the nexus between changes

in the term spread and future GDP growth. Second, we attempt to decompose the separate effects of the 'pure expectations' term spread and the term premium on cumulative GDP growth. 
The rest of the paper is organised as follows. A literature review is provided in the following section, while data and sample separation are described in section 3. Results are presented in the fourth section, beginning with analysis of a basic regression model for cumulative GDP growth. Alternative specifications of the basic model are then considered. The last part of this section uses the expectations model of the term structure to estimate the importance of the term premium in driving our results. The fifth section draws conclusions.

\section{Literature Review}

Several arguments have been advanced as to why a move to an inflation-targeting regime reduces the predictive ability of the term spread. An argument sometimes put forward in financial-market commentary concerns the risk premium, the proposition being that under a credible regime longer-term fluctuations in inflation are likely be lower than otherwise, cutting the risk premium on longterm nominal securities. However, whether a cut in the inflation risk premium leads to a cut in the nominal interest-rate risk premium depends on the relationship between the volatility of the real interest rate and the choice of monetary regime. If, in practice, an inflation-targeting regime achieves a greater degree of price stability at the expense of higher volatility in real variables, then it is not clear a priori that the volatility of the long term nominal rate, and hence the risk premium, will decline under inflation targeting. Our empirical analysis is designed to throw light on this issue.

The second line of argument is based on models in which the expectations model of the term structure applies - so the risk premium is exogenous. At its simplest, the term spread measures the difference between current shortterm rates and the long-term average of future short-term rates, and hence provides a measure of the stance of monetary policy. On this interpretation, the measure is likely to change as monetary regimes change. The argument of Bordo and Haubrich (2004) is as follows. Under a credible monetary policy, an inflationary shock has no effect on the rate on long bonds but increases the 
short-run nominal rate. A temporary adverse real shock also increases the short rate as people attempt to smooth consumption while the long rate is, again, unaffected by the temporary shock. So, while a fall in the term spread could result from either a real or inflationary shock, it is only in the former case that a fall in the spread is associated with a fall in activity.

They then consider the case where the lack of a credible inflation target is characterised in terms of inflation being a random walk. In that case an inflationary shock is expected to persist and both long and short nominal rates rise by an equal amount, leaving the term spread unchanged. A temporary real shock, however, leads to a cut in the spread in the same way as before. Reasoning along these lines then leads Bordo and Haubrich to conclude that, since the noisy signal from inflationary shocks is absent in the 'non-credible policy' periods, one is more likely to find that falls in the term spread are associated with falls in real activity in these periods. This proposition is not rejected by their empirical analysis, based on United States data from 1879 onwards.

Ellingsen and Söderström (2001) develop a closed-economy model the conclusions of which can be interpreted in a similar way. Their model is based on Svensson $(1997,1999)^{1}$. The central bank sets the cash rate by optimising a quadratic intertemporal loss function which has as arguments deviations of inflation and output from their target values (zero). The model comprises (i) a Phillips curve where the change in inflation depends on the deviation of output from its full-employment equilibrium and an i.i.d. inflation shock, (ii) an aggregate demand equation in which the change in the output deviation depends on the real interest rate and an i.i.d. demand shock, (iii) a modified expectations theory of the term structure in which the $n$-period rate is the average of expected future short rates up to maturity $n$-1, plus an exogenous term premium.

\footnotetext{
${ }^{1}$ An implication of their model - that the response of the yield curve to shocks depends on whether or not the private sector attributes monetary policy actions to changes in preferences for inflation stabilisation - has been tested for Australia and New Zealand over the period 1989 - 2003 by Claus and Dungey (2006). They find some support for this proposition for Australia, but results for New Zealand are weaker.
} 
Ellingsen and Söderström (2001) consider two cases. In the 'symmetric information' case, the private sector has the same information set as the central bank and also knows central bank preferences, summarised by $\lambda$, which is the relative preference weight on output stabilisation. In this case, they show that interest rates of all maturities are positively related to both supply (Phillips curve) and demand shocks, with the magnitude diminishing with maturity.

They then consider the asymmetric-information case where the current value of $\lambda$ is known only to the bank. This case, too, can be interpreted as lack of a credible monetary policy. Ellingsen and Söderström (2001) show that, in this case, interest rates on long bonds move in the opposite direction to the innovation in the (short) central-bank rate. For example, a supply shock which generates an increase in the bank-rate would also lead to a clockwise rotation in the yield curve (short rates rising and long rates falling) if the bank's action revealed its preferences as being tough on inflation (a lower $\lambda$ than the private sector had previously believed).

It is therefore a common prediction of both these models - Bordo and Haubrich (2004) and Ellingsen and Söderström (2001) - that one is more likely to find that that changes in the term spread help forecast GDP growth in periods in which the credibility of monetary policy is low.

There is a number of Australian analyses of the predictive content of the term spread, including Lowe (1992), Alles (1995), Karfakis and Moschos (1995), Fisher and Felmingham (1998) and Karunaratne (1999). Karfakis and Moschos use a bivariate VAR analysis to explore the predictive power of the term spread for the short interest rate, finding that the spread Granger-causes changes in the short rate, using both monthly and quarterly data over the period 1984 to 1991.

The other four studies are more closely related to the present paper. Lowe (1992) and Alles (1995) investigate stability of the relationship between the nominal term spread and cumulative real GDP growth over two subsamples, with the break between them occurring in 1982(2). They use a variety of definitions of short and long interest rates, and hence a variety of definitions of the term 
spread. They show that there is a stronger relation between the term spread in the latter of the two sub-samples; that the term spread performs better than indexes of leading indicators; and that the forecasting performance of the term spread is highest for cumulative GDP growth from two to eight quarters ahead. Karunaratne (1999) generally confirms these results, but does not investigate sub-sample stability. Fisher and Felmingham (1998) test the implication of the consumption CAPM model that the real term spread should forecast changes in real consumption spending, finding [over the sample 1983(4) to 1995(4)] that the spread is useful for forecasting real nondurable consumption growth over a two year horizon.

To the extent that they analyse the stability of the yield-spread relationship, the choice of sample periods for these earlier studies is determined by deregulation of Australian interest rates - the authorities moved from a tap system to a tender system for issuing Treasury notes in December 1979, and for government bonds in July 1982. It is argued that the information content of the yield curve is likely to increase as interest rates are market determined, making it more likely that the term spread is predictor of economic activity. Lowe (1992) and Alles (1995) confirm this to be the case, finding that the forecasting performance of the term spread, using a variety of measures of the spread, improves in the second of their two sub-samples which begins in 1982(3). However none of these earlier studies are able to test whether the forecasting performance of the termspread relationship is sensitive to the adoption of an inflation-targeting regime, which in this paper we take to have occurred in the first quarter of 1993.

To summarise, we adopt a two-stage approach to testing the stability of the relationship between the term spread and output. First we test whether the relationship between the term spread and output is stable across monetary regimes. Then, to provide a sharper test of the theoretical models described above, we enquire as to whether the effect of the spread depends on monetary policy actions, and whether the source of any instability lies in a change in the effect of the risk premium, or a change in effect of the perfect-foresight term spread. A finding that the perfect-foresight term spread is less effective in 
forecasting GDP growth under inflation targeting would support the predictions of Bordo and Haubrich (2004) and Ellingsen and Söderström (2001).

\section{Data}

All data are quarterly and range from 1972(1) - 2006(4). Quarterly interest rates (the cash rate and 5 year bond rates) are the mean of three monthly annualised yields, obtained from Reserve Bank Bulletin Tables F01 and F02. We use averages of monthly data, rather than end-of-quarter data, so as to facilitate comparison with Alles (1995). Although zero-coupon yields have been constructed for the United States these data are not, to our knowledge, available for Australia. While previous authors have used a multiplicity of definitions of the term spread, space constraints limit our analysis to the 5 year - cash rate measure of the term spread ${ }^{2}$.

The GDP growth series are derived from 2003-04 base-period seasonally adjusted chain volume GDP. Cumulative measures of future GDP growth $(400 / k) \ln \left(y_{t+k} / y_{t}\right)$ - are used as the dependent variable ${ }^{3}$. In the following textual discussion this variable is denoted CG2 and so on to refer to, for example, $(400 / 2) \ln \left(y_{t+2} / y_{t}\right)$. Data were tested for stationarity using ADF tests over the longest available sample period (1959 to 2006 for the various transformations of GDP data, and 1972 to 2006 for the term spread and its two constituents), and the null of a unit root was rejected in all cases.

\footnotetext{
${ }^{2}$ The monthly 'cash-rate' data are a splice of the series for the 11 am call rate and the interbank cash rate. Monthly cash-rate data are within-month averages of daily data, while available 5-year bond data are end-of-month data. Interest-rate data are not seasonally adjusted.

${ }^{3}$ Analyses based on so-called marginal growth models with the dependent variable defined as 2 quarter growth $k$ periods ahead (i.e. $\left.(400 / n) \ln \left(y_{t+k} / y_{t+k-2}\right)\right)$ proved uninformative, as did Probit and Logit models, with the dependent categorical variable defined in terms of GDP slowdowns of varying degrees of severity. In some sub-samples there is only a small number of recession episodes which limits the extent to which stability across monetary regimes can be examined. Further detail can be provided on request from the authors.
} 
Sub-samples have been chosen as follows:

Sample One: (Early): 1972(1) - 1984(4)

Sample Two (Checklist) : 1985(1) - 1992(4)

Sample Three: (Targeting) 1993(1) - 2006(4)

The beginning and end points for the full sample are determined by the availability of data at the time of writing. The beginning of the Targeting sample represents the start of the Reserve Bank's inflation-targeting regime ${ }^{4}$. Choosing the break between the Early and Checklist samples is a little more problematic, as monetary deregulation occurred gradually in Australia. As mentioned earlier, official interest rates were deregulated in stages, starting in 1979. The exchange rate was floated in December 1983. Finally, the policy of targeting the growth rate of M3 was formally abandoned in January 1985. On this basis, we choose 1985(1) as the beginning of Checklist sample, during which monetary policy was conducted by adjusting interest rates in response to variation in a 'checklist' of economic variables.

Lowe (1992) suggests that interest rates determined under the tender system have more closely reflected market conditions and expectations than was the case with the tap system. While this may be true for one of the two rates, it is an empirical issue whether the spread has been more closely reflective of market conditions in later sample periods - changing patterns in the component series can be seen in the monthly data shown in Figure $1^{5}$, where the 5 -year bond rate was set by Treasury in earlier periods, with the cash rate being set by the Reserve Bank in later periods. So, although we do not necessarily disagree with Lowe's argument regarding the changing nature of information incorporated in the term spread between the Early and Checklist samples, the main focus in what follows is in the comparison between the Checklist and Targeting regimes.

\footnotetext{
${ }^{4}$ Although the inflation-targeting regime was formalised in 14 August 1996, by an exchange of letters between the then Treasurer and the designate Reserve Bank Governor, most accounts recognise that the Reserve Bank had started targeting inflation early in 1993 - see for instance Grenville (1997) or Macfarlane (1998).

${ }^{5}$ Although our econometric work uses quarterly data, Figure 1 is based on monthly data so as to more clearly highlight changes in the time-series properties of the various series.
} 


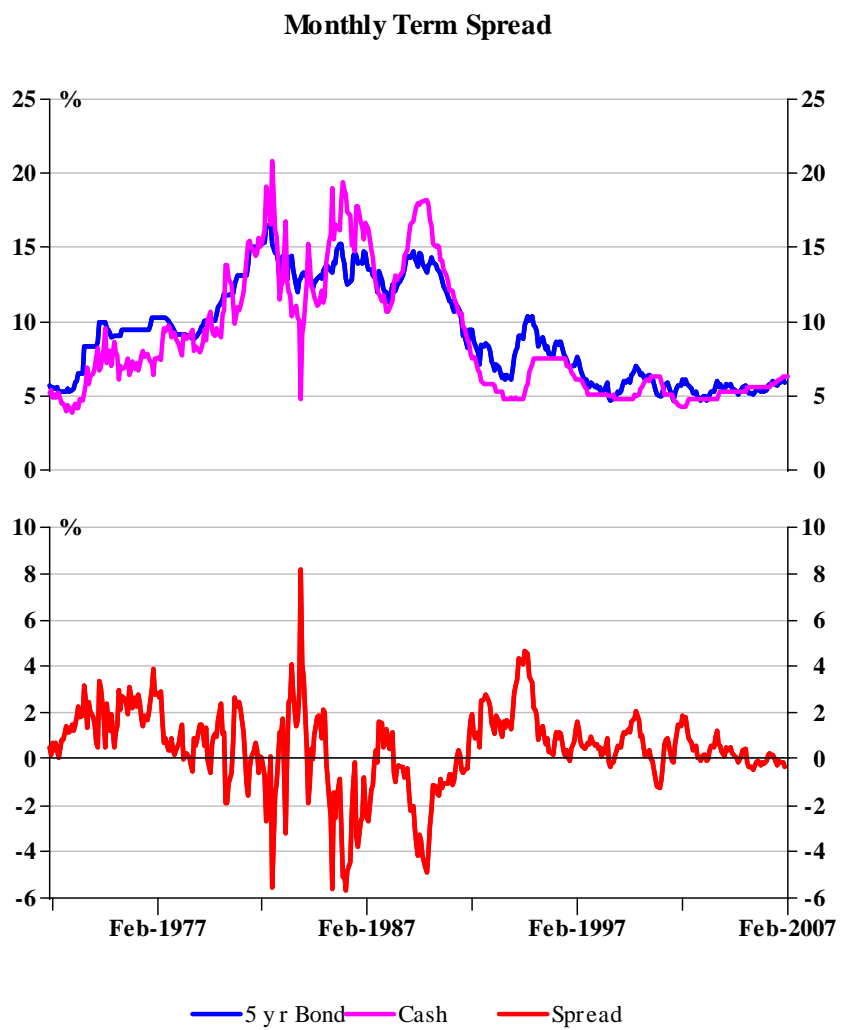

Figure 1 Term Spread and Components

A final consideration concerns the effects of changes in the private-sector information set, rather than changes in central bank objectives. Instead of defining sub-samples in terms of the break between the checklist and inflationtargeting, it may be more important to consider the effect of changes in the way monetary policy was communicated to Australian financial markets. In this respect a break occurred in January 1990, after which the Reserve Bank's monetary policy actions were communicated immediately. The post-1990 period also coincides with rapid disinflation which occurred before the adoption of inflation targeting. Accordingly, the robustness of the Targeting results will be 
checked by analysing a Post 1990 sample, running from 1990(1) to 2006(4) .

\section{Results}

This section comprises several parts. We first investigate stability across subsamples using a regression relating cumulative growth to the term spread and lagged growth rates. Several variants of the basic regression are then examined for evidence of specific monetary-policy effects. The last part of this section uses the expectations theory of the term structure to disentangle the 'expectedrate-change' and 'term premium' effects.

\subsection{Basic regression}

The basic regression equation (1) is used to quantify the relationship between the term spread and cumulative GDP growth over the following $k$ quarters, where $s$ represents the term spread.

$$
(400 / k) \ln \left(y_{t+k} / y_{t}\right)=\alpha_{0}+\alpha_{1} s_{t}+\sum_{j=0}^{3} \beta_{j}(400) \ln \left(y_{t+j} / y_{t+j-1}\right)+\epsilon_{t}
$$

We allow for the possibility that the persistence of output growth means that past values of GDP growth are also useful predictors of cumulative growth ${ }^{7}$. The definition of the dependent variable implies overlapping data resulting in autocorrelated errors - we therefore apply a Newey-West (1987) correction.

Detailed results are provided in Appendix Table 1, and are summarised in Figure 2 (as in later Figures, red (upward sloping hash) columns indicate significance at 1\%; blue (downward sloiping has) indicates significance at 10\%). In Figure 2, the first of each pair of vertical bars represents the estimate of

\footnotetext{
${ }^{6}$ If $1990(1)$ is taken as the break point, there are too few observations in the shorter Checklist sample for meaningful analysis, so only Post 1990 results are reported.

${ }^{7} \mathrm{~A}$ more general approach would be to estimate a VAR in the term spread and output growth, and to generate $k$-step ahead forecasts by iterating the VAR. We follow Stock and Watson (2003) in using a linear regression specification.
} 
$\alpha_{1}$ in a version of (1) which excludes past GDP growth rates as regressors; the second of the set of bars is the estimate of $\alpha_{1}$ obtained when conditioning on past GDP growth. Horizontal axis labels refer to value of $k$ in the dependent variable CGk.

First, the estimated spread coefficient is always positive suggesting that, in accord with priors, an increase in the yield spread precedes an increase in growth. The estimates for the unconditional version of (1) also favour our theoretical priors with respect to sub-sample properties - in the Checklist sample, estimated values for forecasting cumulative growth are positive for CG2 and CG4 (significant at 1\% and 10\% respectively). During the Targeting sample, estimated values of $\alpha_{1}$ are numerically smaller and never significantly different from zero.

When estimates of $\alpha_{1}$ are conditioned on past GDP growth rates, they are insignificant at all time horizons for cumulative growth in the Checklist period, but the estimate is significant for CG2 in the Targeting period ( $p$-value 0.098).

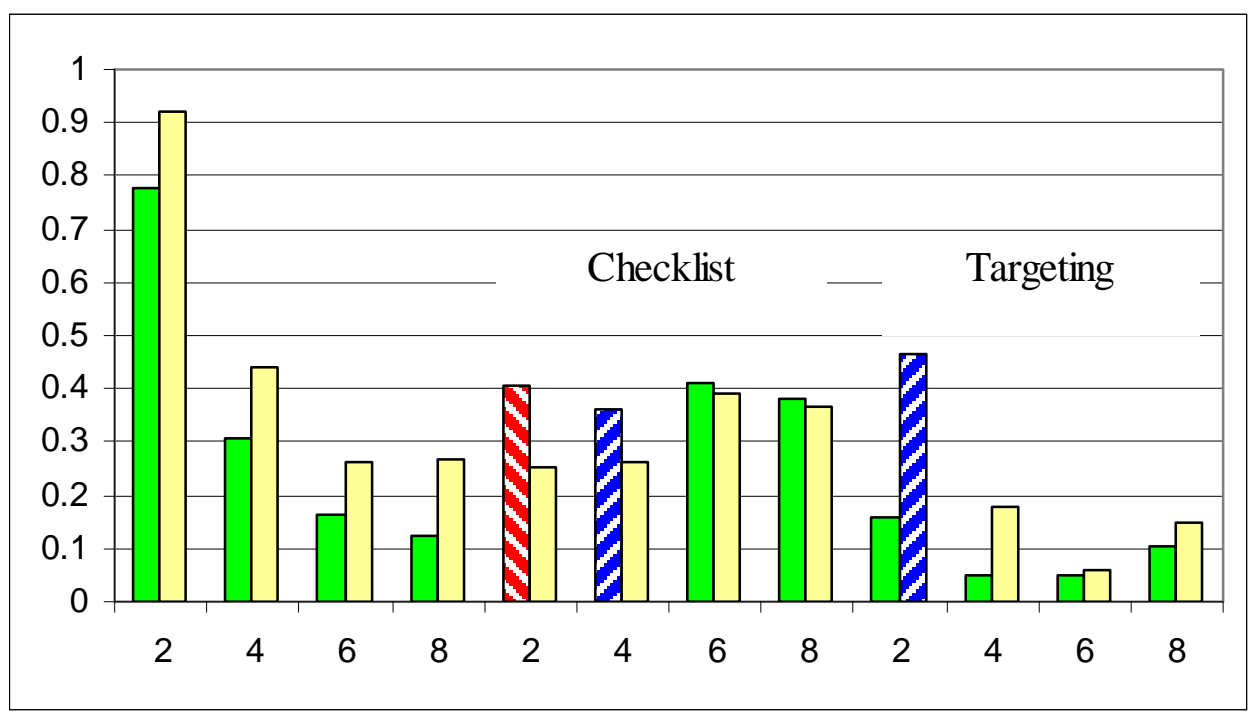

Figure 2 Estimates of $\alpha_{1}$ : Unconditional and Conditional models. 
Our results for the Checklist period give a different picture than that provided by Lowe (1992). In terms of our notation, his conditional model can be written as

$$
(400 / k) \ln \left(y_{t+k} / y_{t}\right)=\alpha_{0}+\alpha_{1} s_{t}+\alpha_{2} \operatorname{Lead}_{t}+\epsilon_{t}
$$

where Lead is the annualised percentage change in the Index of Leading Indicators over the previous quarter. Over the sample period 1982(3)-1991(2) he finds that, unlike the results shown in Figure 2, the term spread is significant in both the unconditional and conditional models for CG4, CG6 and CG8, and that the numerical values of the estimated values of $\alpha_{1}$ are virtually the same across the two models. Evidently, the choice of conditioning variable - Lead in Lowe's model, and past GDP growth rates in Figure 2 - plays a role in assessing the forecasting performance of the term spread $^{8}$.

A comparison of results for the Target and Post 1990 samples is provided in Figure 3. For the unconditional model, the coefficient on the term spread is positive, larger than for the Targeting sample, and significant (at 10\%) for all time horizons. This pattern is maintained in the conditional model $-\widehat{\alpha}_{1}$ is positive and greater than in the Target sample; it is significant at horizons 2,6 and 8 .

The preliminary conclusion is that, comparing the Checklist and Targeting periods, results do not support the predictions of Bordo and Haubrich (2004) and Ellingsen and Söderström (2001), that the term spread is less likely to be significant in an inflation-targeting regime. When the regression is conditioned on past GDP growth the term spread is not significant in the Checklist sample, but it is significant (for a two-quarter time horizon) in the targeting sample. If attention is focussed on the Post 1990 sample, the spread is almost always significant and positive, in both the unconditional and conditional models.

\footnotetext{
${ }^{8}$ It should be emphasised that our Checklist sample does not overlap with the 'deregulated' sample of Lowe (1992), and that our GDP data are of more recent vintage than those used by him.
} 


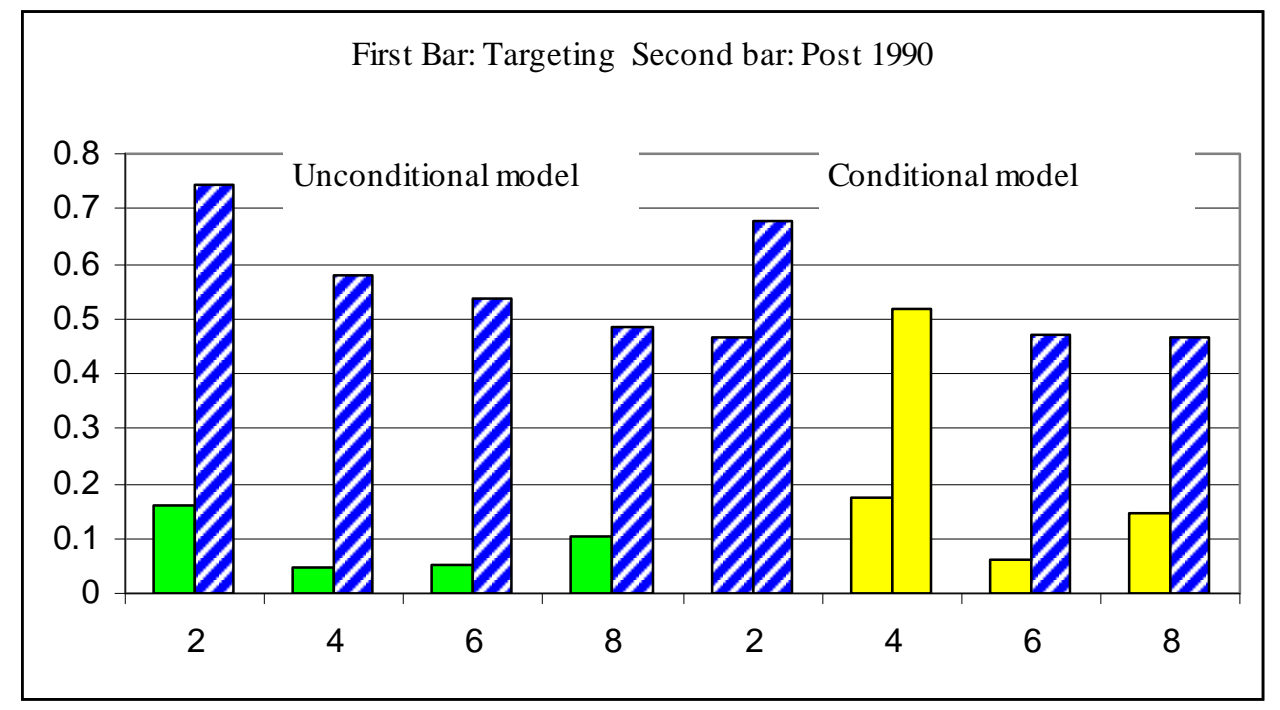

Figure 3 Estimates of $\alpha_{1}$ in Targeting and Post 1990 samples.

We now provide further analysis of the cumulative growth regression to test if the predictive power of the term spread can be better understood by specifying alternative models ${ }^{9}$. Following Dotsey (1998), (1) is augmented by additional terms that explore the effect of tight monetary policy. The intuition supporting this is that yield inversions (negative term spreads) may simply be a function of tight monetary policy, and hence it is only in periods where the cash rate is rising that the yield curve forecasts a slowdown in growth. Alternatively, it may be that tight monetary policy, and not a yield inversion, precedes any slowdown in growth, and hence the addition of the monetary policy proxy term may reduce the significance of the term spread coefficient.

\footnotetext{
${ }^{9}$ We have also explored nonlinearities in the relationship. This approach decomposes the spread into three components: normal values; unusually high values; and unusually low values, to test if these different ranges result in different relationships between the spread and economic growth. No significant nonlinearities were found.
} 


\subsection{Effect of monetary tightening}

To consider the effect of monetary tightening, the following regression is performed:

$$
\begin{aligned}
& (400 / k) \ln \left(y_{t+k} / y_{t}\right) \\
= & \alpha_{0}+\alpha_{1} d_{t} s_{t}+\alpha_{2} d_{t}+\alpha_{3} s_{t}+\sum_{j=0}^{3} \beta_{j}(400) \ln \left(y_{t+j} / y_{t+j-1}\right)+\epsilon_{t}
\end{aligned}
$$

where the dummy variable $d_{t}$ takes the value 1 if the cash rate is raised by at least 50 basis points over the preceding two quarters, $s_{t}$ again represents the term spread, and $d s_{t}$ interacts the dummy variable with the spread. As before, the expected sign on the coefficient on the spread $\left(\alpha_{3}\right)$ is positive, while the expected signs for $\alpha_{1}$ and $\alpha_{2}$ are positive and negative respectively. Summary

results are shown in Figures 4 and 5, with details provided in the Appendix.

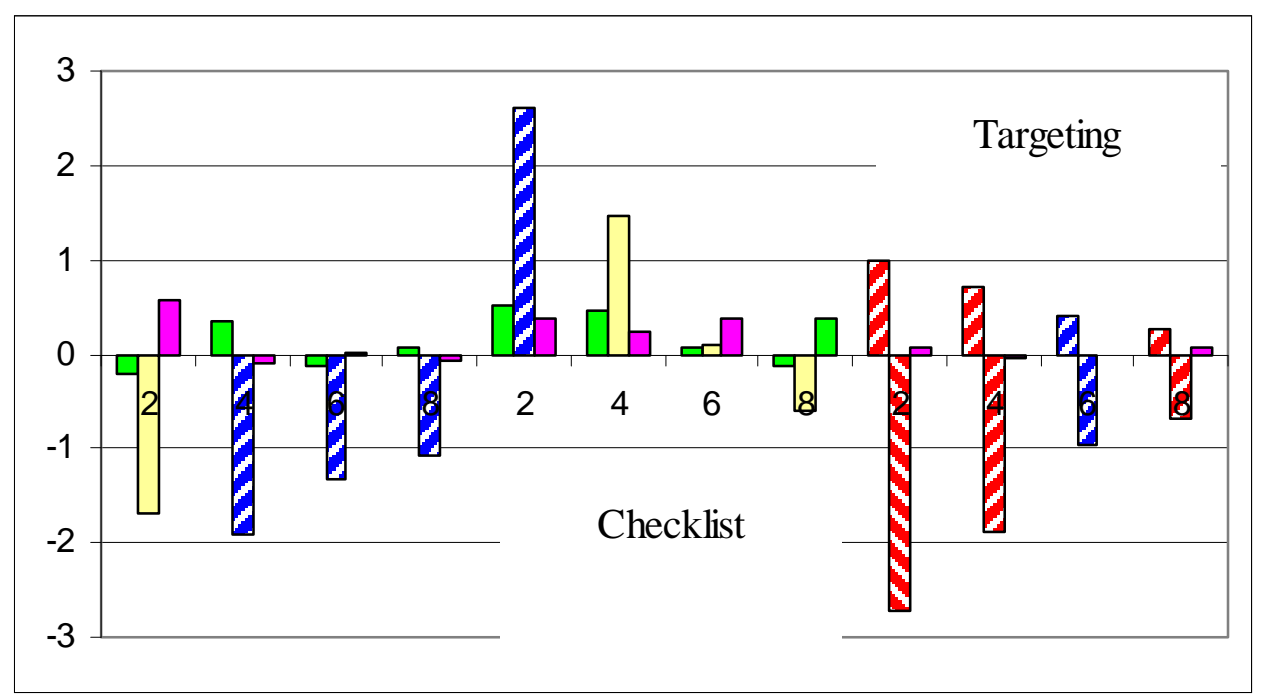

Figure 4 Estimates of $\alpha_{1}, \alpha_{2}, \alpha_{3}$ : Not conditioned on past GDP growth. 


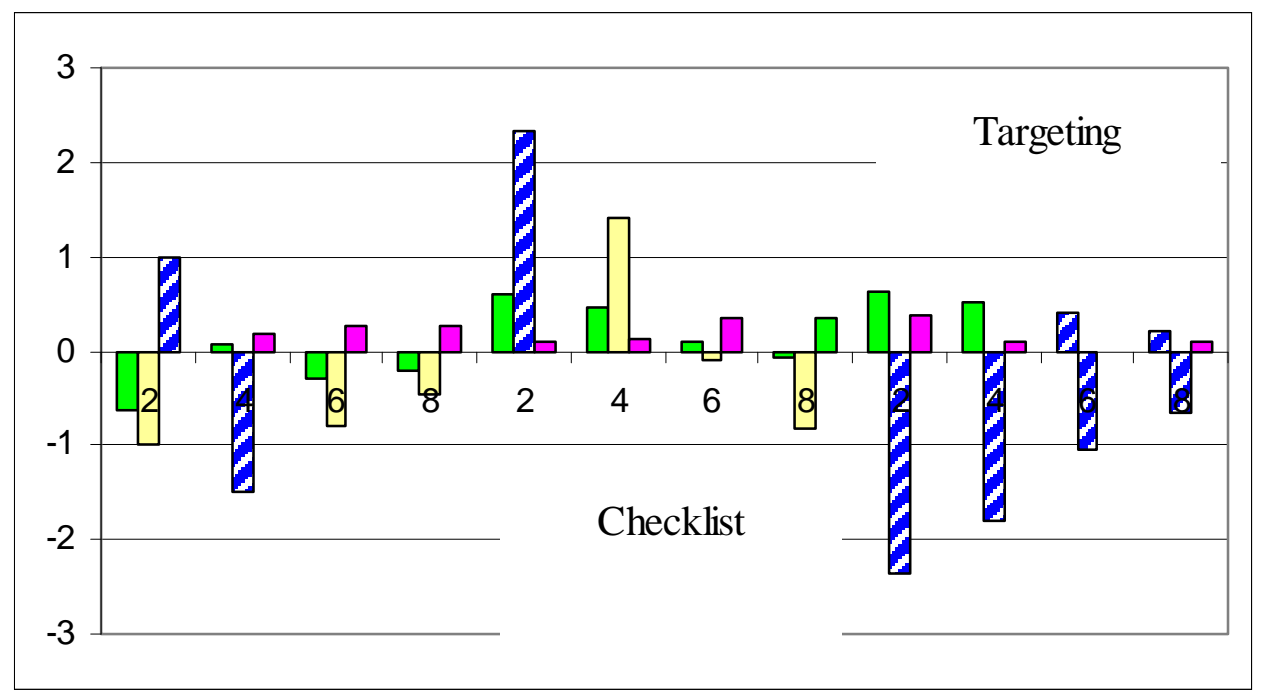

Figure 5 Estimates of $\alpha_{1}, \alpha_{2}, \alpha_{3}$ : Conditioned on past GDP growth.

Restricting comparison between the unconditional and conditional models to the two sample periods of most interest - the Checklist and Targeting samples - it can be seen that conditioning on past GDP growth rates has little effect on the overall flavour of the estimates of (3).

Results for the Checklist sample are difficult to interpret. The monetary tightening dummy has the wrong sign for CG2 and CG4 in both models, and is significantly greater than zero for CG2 in the conditional model. We interpret these results to indicate that, because it was not until 1990 that the Reserve Bank signalled changes in monetary policy by announcing changes in the cash rate, our tightening dummy may not reflect the way in which monetary policy was implemented and hence market perceptions of tightening in monetary policy which had actually taken place.

Results for the Targeting sample are more clear-cut. The tightening dummy is significant at all time horizons and the interaction term is significant at all time horizons in the unconditional model, and for CG6 and CG8 in the conditional model. This suggests that when monetary policy is tight the spread has the 
effect of reducing cumulative growth. The interaction term is also significant at all time horizons in the unconditional model, and for CG6 and CG8 in the conditional model. The coefficient on the spread itself is not significant at any time horizon in either model.

Now turn to a comparison between the Post 1990 and Targeting samples provided in Tables 2A and 2B in the Appendix. In the Post 1990 unconditional model $\alpha_{3}$, the coefficient on the spread, is positive and significant at time horizons 2,6 and 8 . The coefficient on the tightening dummy, $\alpha_{2}$, is significant and negative at time horizon 2. However in the conditional model, $\alpha_{3}$ is never significant but $\alpha_{2}$ is significant and negative at time horizons 2 and 4 . If more weight is placed on the conditional model, there is some commonality in results across the two samples - in both the Post 1990 and Targeting regimes the term spread adds extra information when monetary policy is tight, but not otherwise.

\section{Decomposition of the term spread}

The second extension to the basic model is to use the pure expectations model of the term structure to decompose the effects of the term spread on cumulative GDP growth into two components - the rationally-expected change in short-term interest rates and the term or risk premium. Using the approach of Hamilon and Kim (2002), the term spread is decomposed as follows:

$$
i_{t}^{5 y e a r}-i_{t}^{\text {cash }}=\left(\frac{1}{n} \sum_{j=0}^{n-1} E_{t} i_{t}^{\text {cash }}-i_{t}^{\text {cash }}\right)+\left(i_{t}^{\text {syear }}-\frac{1}{n} \sum_{j=0}^{n-1} E_{t} i_{t}^{\text {cash }}\right)
$$

Hence the spread contains expectations of future changes in short-term interest rates, $\left(\frac{1}{n} \sum_{j=0}^{n-1} E_{t} i_{t}^{\text {cash }}-i_{t}^{\text {cash }}\right)$, and a term premium for risk or liquidity, denoted $\left(i_{t}^{5 y e a r}-\frac{1}{n} \sum_{j=0}^{n-1} E_{t} i_{t}^{\text {cash }}\right)$. However we note that by taking an arithmetic rather than geometric mean of the various cash rates, Hamilton and Kim (2002) introduce an approximation error into the data - in its more usual geometric- 
mean form the first bracketed term in would be $100\left(\left[\prod_{j=0}^{n-1}\left(1+\frac{E_{t} i_{t+j}^{\text {cash }}}{400}\right)\right]^{\frac{4}{n}}-1\right)$ with the expectation replaced by the actual value of the future cash rate on the perfect-foresight assumption. That this approximation error may have important implications can be seen from Figure 6, which plots the averaging error (the difference between the 20-quarter arithmetic and geometric means of the cash rate) and the term spread. Clearly, the averaging errror is large relative to the term spread so, in what follows, our decomposition is based on the geoemetric mean $^{10}$.

\footnotetext{
${ }^{10}$ Data shown in Figure 6 for the averaging error terminate 20 quarters before the end of the sample period because of the forward-looking nature of the expectations model in (4). The averaging error increases nonlinearly with the cash rate; for this reason the error is numerically larger than in Hamilton and Kim's (2002) study. As a separate exercise we have investigated the effect of averaging error on Hamilton and Kim's results for the United States over their 1953 to 1988 sample. Their results are hardly affected by the use of different averaging methods.
} 


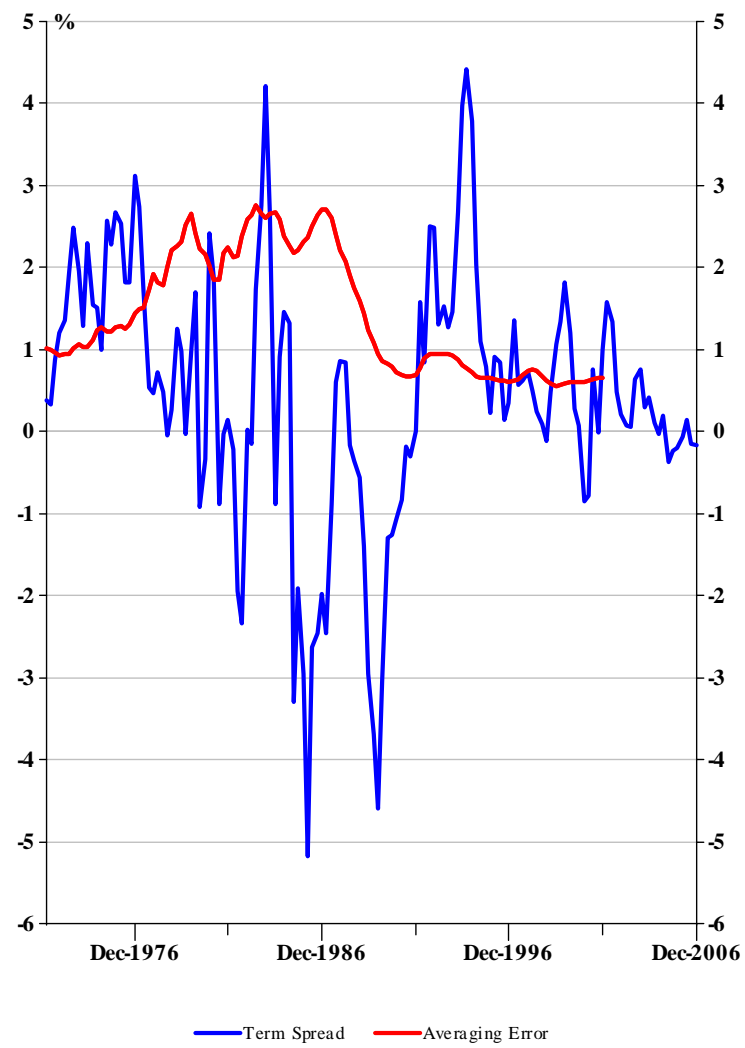

Figure 6 Arithmetic-mean averaging error

Substituting the decomposition into (1), we have:

$$
\begin{gathered}
(400 / k) \ln \left(y_{t+k} / y_{t}\right)=\alpha_{0}+\alpha_{1}\left(100\left(\left[\prod_{j=0}^{n-1}\left(1+\frac{E_{t} i_{t+j}^{\text {cash }}}{400}\right)\right]^{\frac{4}{n}}-1\right)-i_{t}^{\text {cash }}\right) \\
+\alpha_{1}\left(i_{t}^{5 y e a r}-100\left(\left[\prod_{j=0}^{n-1}\left(1+\frac{E_{t} i_{t+j}^{\text {cash }}}{400}\right)\right]^{\frac{4}{n}}-1\right)\right)+\epsilon_{t}
\end{gathered}
$$

Generalising to allow for different coefficients on the two bracketed terms we 
have

$$
\begin{gathered}
(400 / k) \ln \left(y_{t+k} / y_{t}\right)=\alpha_{0}+\lambda_{1}\left(100\left(\left[\prod_{j=0}^{n-1}\left(1+\frac{E_{t} i_{t+j}^{\text {cash }}}{400}\right)\right]^{\frac{4}{n}}-1\right)-i_{t}^{\text {cash }}\right) \\
+\lambda_{2}\left(i_{t}^{\text {yyear }}-100\left(\left[\prod_{j=0}^{n-1}\left(1+\frac{E_{t} i_{t+j}^{\text {cash }}}{400}\right)\right]^{\frac{4}{n}}-1\right)\right)+\epsilon_{t}
\end{gathered}
$$

If agents make interest-rate forecast errors, they may be defined as:

$v_{t+n}=100\left(\left[\prod_{j=0}^{n-1}\left(1+\frac{i_{t+j}^{\text {cash }}}{400}\right)\right]^{\frac{4}{n}}-1\right)-100\left(\left[\prod_{j=0}^{n-1}\left(1+\frac{E_{t} i_{t+j}^{\text {cash }}}{400}\right)\right]^{\frac{4}{n}}-1\right)$

which then defines the following:

$$
\begin{gathered}
(400 / k) \ln \left(y_{t+k} / y_{t}\right)=\alpha_{0}+\lambda_{1}\left(100\left(\left[\prod_{j=0}^{n-1}\left(1+\frac{E_{t} i_{t+j}^{\text {cash }}}{400}\right)\right]^{\frac{4}{n}}-1\right)-i_{t}^{\text {cash }}\right) \\
+\lambda_{2}\left(i_{t}^{5 y e a r}-100\left(\left[\prod_{j=0}^{n-1}\left(1+\frac{E_{t} t_{t+j}^{\text {cash }}}{400}\right)\right]^{\frac{4}{n}}-1\right)\right)+\epsilon_{t}
\end{gathered}
$$

where

$$
\zeta_{t}=\epsilon_{t}+\left(\lambda_{2}-\lambda_{1}\right) \nu_{t+n}
$$

Because the bracketed terms on the right hand side of (8) may be correlated with the disturbance term, we use instrumental-variables estimation using variables known at time $t$ as instruments - under the assumptions of rational expectations, variable values known at time $t$ should be uncorrelated with 
the residuals, and $\nu_{t+n}$ should equal zero on average ${ }^{11}$. We obtained results with two alternative sets of instruments: a constant, $i_{t}^{\text {5year }}$ and $i_{t}^{\text {cash }}$; and a constant, $i_{t}^{\text {5year }}, i_{t}^{\text {cash }}$, and the four lagged values of the GDP growth rate, (400) $\ln \left(y_{t+j} / y_{t+j-1}\right)$, used previously as regressors in the OLS estimation of the conditional models. Results were similar for both sets of instruments, so only those for the smaller set are reported here.

Results, using a constant and current values of the cash rate and the 5 year bond rate as instruments, are provided in Figure 7, with details in Table 3A of the Appendix.

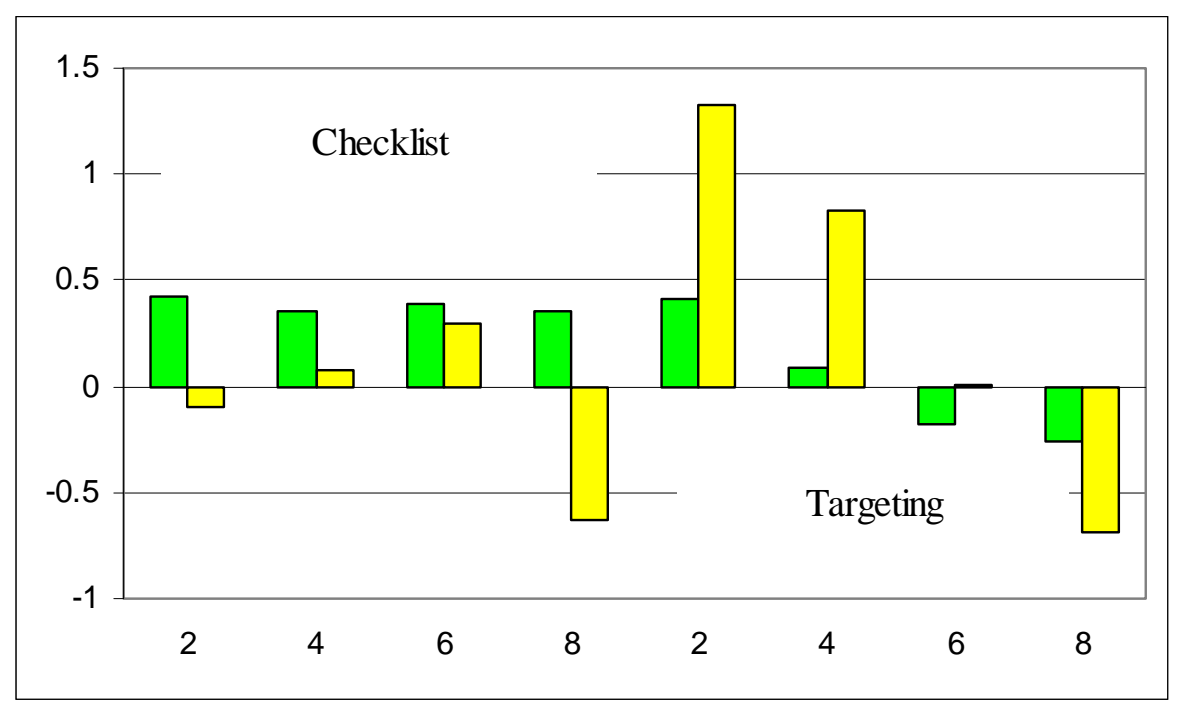

Figure 7 Estimates of $\lambda_{1}$ and $\lambda_{2}$, eqn (8).

Although there appear to be large changes in some of the numerical estimates of $\lambda_{1}$ and $\lambda_{2}$ between the Targeting and Checklist samples, the estimates are not significantly different from zero. So these results throw no light on the question of interest in this paper - whether the change in monetary regime has had

\footnotetext{
${ }^{11}$ Rational expectations are necessarily implied by the derivation of the model, as the expected future path of interest rates is captured by taking the mean of the actual path of future interest rates. Any forecasting errors are present in the residuals (10). Rational expectations hence assume that all available information is already incorporated into the forecast.
} 
any impact on the relationship between the perfect-foresight term spread and cumulative GDP growth. As results in Table 3A of the appendix show, this finding is not dependent on the choice of 1993(1) as the start of the changed monetary regime; the Post 1990 sample yields similar results. Nor are the results dependent on the use of geometric averaging. If arithmetic averaging is used the results in Table $3 \mathrm{~b}$ show that the pattern and size of numerical estimates change, but none are significant.

It is, however, interesting to note that our results contrast with those from Hamilton and Kim (2002) in their study using data from the United States. They estimate (8) using data from $1953(3)$ to $1988(4)$, with the spread defined as the difference between yields on 90-day Treasury bills and the 10 year Treasury bonds. They find that expected changes in interest rates are significant for forecasting growth 12 quarters ahead, while the premium was significant for forecasting growth up to 8 quarters ahead. Hamilton and Kim (2002) find that where both coefficients are significant both are positive and the test of $\lambda_{1}=\lambda_{2}$ is rejected, with $\lambda_{1}$ being larger than $\lambda_{2}$. On this basis they conclude that the most important reason that a negative term spread predicts slower GDP growth in the US is that 'a low spread implies falling future short term interest rates' (p.351), but they are unsuccessful in their attempt to explain the positive sign of $\lambda_{2}$ in terms of the cyclical behaviour of GDP volatility ${ }^{12}$.

\section{Conclusions}

This study has two objectives - to determine the degree to which the Australian term spread can forecast real GDP growth; and to examine whether this relationship, if shown to exist, has changed over time. Our results suggest that over

\footnotetext{
${ }^{12}$ Although Hamilton and Kim (2002) do not investigate the stability of their results across different monetary regimes, Rudebusch et. al. (2007) estimate a model similar to (8); $C G 4_{t}=$ $\alpha_{0}+\lambda_{1}\left(H K_{1}\right)_{t}+\lambda_{2}\left(H K_{2}\right)_{t}+C G 4_{t-4}+\epsilon_{t}$ where $H K_{1}$ and $H K_{2}$ refer to the two elements of the Hamilton-Kim arithmetic-mean decomposition of the 90 day - 10 year term spread. Using US data for the sample1962-2005, they find $\lambda_{1}$ to be significant and positive, but $\lambda_{2}$ is insignificant. Over the shorter sample 1985-2002, neither coefficient is significant.
} 
some periods the term spread has been useful for forecasting cumulative real GDP growth. More specifically, in models in which the term spread is the only regressor, there is some evidence to suggest that the term spread had predictive power in the Checklist sample, but not in the Targeting sample. These results accord with the common perception of a decline in the predictive ability of the term spread in recent times, and appear to support theoretical predictions that the spread should have less predictive power in a inflation-targeting regime.

However we show that these initial results are sensitive to conditioning on other variables which might be useful in forecasting cumulative GDP growth. In the first extension, past values of quarter-on-quarter GDP groth are included as regressors along with the term spread. This extension reverses our earlier conclusions to the extent that there is no significant forecasting value for the term spread in the Checklist period but (for a two-quarter forecasting horizon) the estimated coefficient on the term spread is positive and significant.

The second extension explores whether the term spread has predictive power once changes in the stance of monetary policy are taken into account - changes in stance are captured by a 'tightening dummy' which takes the value 1 if the cash rate is raised by at least 50 basis points over the preceding two quarters. Although the results for the Checklist period are difficult to interpret, there is a reasonably clear finding that in the Targeting regime the term spread adds extra information when monetary policy is tight, but not otherwise. This conclusion also holds if the change in monetary regime is assumed to have taken place in 1990(1), when the Reserve Bank began announcing its changes to monetary policy at the same time as the changes were implemented.

Finally, we decompose the term spread into two components - the expected change in the short term interest rate, and the change in the term premium. Neither component appears to be significant in the Checklist and Inflation Targeting samples. These results are at variance with those obtained by Hamilton and Kim (2002) who explore the significance of the two components for a long post-war sample of data in the United States.

To sum up, it appears that, at least for forecasting Australian cumulative 
GDP growth, the role of the term spread has been somewhat overstated. The term spread loses its influence once other plausible effects are taken into account. 


\section{Appendix}

Table 1 The Term Spread and Cumulative GDP Growth

$$
\begin{aligned}
& \text { OLS Regression } \begin{array}{l}
\text { Equation (1) } \\
(400 / k) \ln \left(y_{t+k} / y_{t}\right)=\alpha_{0}+\alpha_{1} s_{t}+\sum_{j=0}^{3} \beta_{j}(400) \ln \left(y_{t+j} / y_{t+j-1}\right)+\epsilon_{t}
\end{array}
\end{aligned}
$$

\begin{tabular}{llllllll} 
& \multicolumn{4}{c}{ Unconditional model } & \multicolumn{3}{c}{ Conditional model } \\
Sample & $k$ & $\alpha_{1}$ & $p$ value & $\bar{R}^{2}$ & $\alpha_{1}$ & $p$ value & $\bar{R}^{2}$ \\
& 2 & 0.776 & 0.190 & 0.052 & 0.926 & 0.141 & 0.079 \\
1972(1)-1984(4) & 4 & 0.307 & 0.497 & 0.005 & 0.439 & 0.361 & 0.025 \\
& 6 & 0.165 & 0.568 & -0.007 & 0.263 & 0.405 & 0.085 \\
& 8 & 0.123 & 0.484 & -0.009 & 0.268 & 0.192 & 0.199 \\
& & & & & & & \\
1985(1)-1992(4) & 4 & $0.359^{*}$ & 0.064 & 0.080 & 0.262 & 0.317 & 0.019 \\
Checklist & 6 & 0.413 & 0.117 & 0.161 & 0.393 & 0.156 & 0.053 \\
& 8 & 0.384 & 0.154 & 0.178 & 0.365 & 0.177 & 0.064
\end{tabular}

$\begin{array}{llllllll} & 2 & 0.160 & 0.387 & -0.0090 & 0.465^{*} & 0.098 & 0.054 \\ \text { 1993(1)-2006(4)) } & 4 & 0.047 & 0.691 & -0.018 & 0.176 & 0.363 & -0.002 \\ \text { Targeting } & 6 & 0.049 & 0.636 & -0.016 & 0.059 & 0.654 & -0.095 \\ & 8 & 0.104 & 0.130 & 0.003 & 0.147 & 0.144 & -0.076\end{array}$

$\begin{array}{llllllll} & 2 & 0.745^{* *} & 0.053 & 0.173 & 0.678^{* *} & 0.072 & 0.135 \\ 1990(1)-2006(4) & 4 & 0.580^{* *} & 0.077 & 0.177 & 0.519 & 0.100 & 0.131 \\ \text { Post } 1990 & 6 & 0.538^{* *} & 0.055 & 0.243 & 0.470^{* *} & 0.085 & 0.205 \\ & 8 & 0.486^{* *} & 0.031 & 0.291 & 0.468^{* *} & 0.038 & 0.255\end{array}$

Note: ${ }^{*}$ and ${ }^{* *}$ represents $\widehat{\alpha}_{1}$ significant at the $1 \%$ and $10 \%$ level of confidence respectively; estimates corrected for autocorrelation and heteroskedasticity using Newey and West (1987). Coefficients on lagged growth not shown for conditional model. 
Table 2A Monetary tightening, the Term Spread and GDP Growth

OLS Regression Equation (3): Not conditional on lagged GDP growth

$$
(400 / k) \ln \left(y_{t+k} / y_{t}\right)=\alpha_{0}+\alpha_{1} d_{t} s_{t}+\alpha_{2} d_{t}+\alpha_{3} s_{t}+\epsilon_{t}
$$

\begin{tabular}{lllllllll} 
Sample & $k$ & $\alpha_{1}$ & $p$ value & $\alpha_{2}$ & $p$ value & $\alpha_{3}$ & $p$ value & $\bar{R}^{2}$ \\
& 2 & -0.196 & 0.739 & -1.696 & 0.179 & 0.583 & 0.231 & 0.067 \\
\multirow{5}{*}{ Early } & 4 & 0.336 & 0.421 & $-1.899^{* *}$ & 0.030 & -0.110 & 0.803 & 0.049 \\
& 6 & -0.127 & 0.749 & $-1.337^{* *}$ & 0.058 & 0.003 & 0.994 & 0.078 \\
& 8 & 0.078 & 0.832 & $-1.084^{* *}$ & 0.041 & -0.074 & 0.785 & 0.039 \\
& & & & & & & & \\
Checklist & 2 & 0.513 & 0.381 & $2.621^{* *}$ & 0.027 & 0.383 & 0.490 & 0.139 \\
& 4 & 0.459 & 0.313 & 1.458 & 0.215 & 0.243 & 0.646 & 0.087 \\
& 8 & $-0.062^{* *}$ & 0.846 & 0.096 & 0.910 & 0.386 & 0.387 & 0.102 \\
& & & 0.625 & -0.597 & 0.232 & 0.388 & 0.269 & 0.138 \\
& 2 & $0.991^{*}$ & 0.010 & $-2.725^{*}$ & 0.008 & 0.057 & 0.786 & 0.143 \\
& 4 & $0.718^{*}$ & 0.001 & $-1.896^{*}$ & 0.002 & -0.0364 & 0.821 & 0.148 \\
Targeting & 6 & $0.397^{* *}$ & 0.016 & $-0.958^{* *}$ & 0.018 & -0.006 & 0.965 & 0.044 \\
& 8 & $0.251^{*}$ & 0.000 & $-0.674^{*}$ & 0.004 & 0.068 & 0.353 & 0.028 \\
& & & & & & & & \\
& 2 & 0.270 & 0.597 & $-1.788^{* *}$ & 0.094 & $0.779^{* *}$ & 0.077 & 0.204 \\
& 4 & 0.069 & 0.854 & -1.026 & 0.131 & 0.612 & 0.108 & 0.189 \\
& 6 & -0.187 & 0.547 & -0.246 & 0.621 & $0.578^{* *}$ & 0.067 & 0.233 \\
& & -0.205 & 0.392 & -0.142 & 0.683 & $0.524^{* *}$ & 0.037 & 0.285
\end{tabular}

Note: ${ }^{*}$ and ${ }^{* *}$ represents $\widehat{\alpha}_{1}$ significant at the $1 \%$ and $10 \%$ level of confidence respectively; estimates corrected for autocorrelation and heteroskedasticity using Newey and West (1987). 
Table 2B Monetary tightening, the Term Spread and GDP Growth

OLS Regression Equation (3): Conditional on lagged GDP growth

$(400 / k) \ln \left(y_{t+k} / y_{t}\right)=\alpha_{0}+\alpha_{1} d_{t} s_{t}+\alpha_{2} d_{t}+\alpha_{3} s_{t}+\sum_{j=0}^{3} \beta_{j}(400) \ln \left(y_{t+j} / y_{t+j-1}\right)+\epsilon_{t}$

\begin{tabular}{lllllllll} 
Sample & $k$ & $\alpha_{1}$ & $p$ value & $\alpha_{2}$ & $p$ value & $\alpha_{3}$ & $p$ value & $\bar{R}^{2}$ \\
& 2 & -0.622 & 0.365 & -0.996 & 0.383 & 1.002 & 0.081 & 0.086 \\
& 4 & 0.059 & 0.905 & -1.490 & 0.038 & 0.169 & 0.747 & 0.046 \\
\multirow{3}{*}{ Early } & 6 & -0.302 & 0.445 & -0.783 & 0.114 & 0.251 & 0.507 & 0.121 \\
& 8 & -0.204 & 0.597 & -0.458 & 0.224 & 0.272 & 0.412 & 0.208
\end{tabular}

$\begin{array}{ccccccccc} & 2 & 0.608 & 0.174 & 2.320 & 0.063 & 0.105 & 0.806 & 0.200 \\ & 4 & 0.471 & 0.288 & 1.408 & 0.235 & 0.116 & 0.792 & 0.016 \\ \text { Checklist } & 6 & 0.086 & 0.798 & -0.089 & 0.921 & 0.339 & 0.408 & -0.023 \\ & 8 & -0.069 & 0.791 & -0.814 & 0.132 & 0.339 & 0.310 & 0.022\end{array}$

$\begin{array}{ccccccccc} & 2 & 0.626 & 0.227 & -2.360 & 0.045 & 0.378 & 0.167 & 0.178 \\ & 4 & 0.506 & 0.108 & -1.808 & 0.017 & 0.099 & 0.639 & 0.167 \\ \text { Targeting } & 6 & 0.415 & 0.076 & -1.033 & 0.029 & -0.027 & 0.864 & -0.022 \\ & 8 & 0.219 & 0.062 & -0.648 & 0.023 & 0.103 & 0.340 & -0.061\end{array}$

$\begin{array}{lllllllll} & 2 & 0.405 & 0.447 & -2.005^{* *} & 0.067 & 0.665 & 0.139 & 0.173 \\ & 4 & 0.158 & 0.666 & -1.254^{* *} & 0.096 & 0.529 & 0.165 & 0.152 \\ \text { Post 1990 } & 6 & -0.051 & 0.873 & -0.406 & -0.482 & 0.494 & 0.131 & 0.190 \\ & 8 & -0.143 & 0.589 & -0.155 & 0.713 & 0.503 & 0.061 & 0.238\end{array}$

Note: ${ }^{*}$ and ${ }^{* *}$ represents $\widehat{\alpha}_{1}$ significant at the $1 \%$ and $10 \%$ level of confidence respectively; estimates corrected for autocorrelation and heteroskedasticity using Newey and West (1987). Coefficients on lagged growth not shown for conditional model. 
Table 3A Geometric Decomposition of Term Spread and GDP Growth

$$
\begin{gathered}
(400 / k) \ln \left(y_{t+k} / y_{t}\right)=\alpha_{0}+\lambda_{1}\left(100\left(\left[\prod_{j=0}^{n-1}\left(1+\frac{E_{t} i_{t+j}^{\text {cash }}}{400}\right)\right]^{\frac{4}{n}}-1\right)-i_{t}^{\text {cash }}\right) \\
+\lambda_{2}\left(i_{t}^{5 y e a r}-100\left(\left[\prod_{j=0}^{n-1}\left(1+\frac{E_{t} t_{t+j}^{\text {cash }}}{400}\right)\right]^{\frac{4}{n}}-1\right)\right)+\epsilon_{t}
\end{gathered}
$$

\begin{tabular}{llllll} 
Sample & $k$ & $\lambda_{1}$ & $p$ value & $\lambda_{2}$ & $p$ value \\
& 2 & 0.787 & 0.114 & 0.194 & 0.523 \\
\multirow{3}{*}{ Early } & 4 & 0.140 & 0.780 & 0.262 & 0.526 \\
& 6 & 0.101 & 0.824 & 0.113 & 0.752 \\
& 8 & 0.184 & 0.564 & -0.034 & 0.895
\end{tabular}

$\begin{array}{cccccc} & 2 & 0.420 & 0.722 & -0.102 & 0.965 \\ & 4 & 0.355 & 0.992 & 0.075 & 0.998 \\ \text { Checklist } & 6 & 0.388 & 0.991 & 0.302 & 0.999 \\ & 8 & 0.353 & 0.993 & -0.628 & 0.997\end{array}$

$\begin{array}{cccccc} & 2 & 0.417 & 0.631 & 1.329 & 0.866 \\ & 4 & 0.083 & 0.896 & 0.833 & 0.885 \\ \text { Targeting } & 6 & -0.176 & 0.999 & 0.003 & 0.999 \\ & 8 & -0.261 & 0.276 & -0.692 & 0.759\end{array}$

$\begin{array}{cccccc} & 2 & 1.127 & 0.774 & 2.489 & 0.916 \\ & 4 & 1.052 & 0.997 & 2.770 & 0.998 \\ \text { Post 1990 } & 6 & 0.666 & 0.769 & 1.130 & 0.934 \\ & 8 & 0.322 & 0.997 & -0.332 & 0.999\end{array}$

Note: Estimation by instrumental variables with a constant, $i_{t}^{5 y e a r}, i_{t}^{\text {cash }}$ as instruments; estimates corrected for autocorrelation and heteroskedasticity using Newey and West (1987). 
Table 3B Arithmetic Decomposition of Term Spread and GDP Growth $(400 / k) \ln \left(y_{t+k} / y_{t}\right)=\alpha_{0}+\lambda_{1}\left(\frac{1}{n} \sum_{j=0}^{n-1} E_{t} i_{t}^{\text {cash }}-i_{t}^{\text {cash }}\right)+\lambda_{2}\left(i_{t}^{\text {syear }}-\frac{1}{n} \sum_{j=0}^{n-1} E_{t} i_{t}^{\text {cash }}\right)+\epsilon_{t}$

\begin{tabular}{llllll} 
Sample & $k$ & $\lambda_{1}$ & $p$ value & $\lambda_{2}$ & $p$ value \\
& 2 & $0.818^{* *}$ & 0.035 & 0.109 & 0.910 \\
\multirow{3}{*}{ Early } & 4 & 0.333 & 0.266 & -0.543 & 0.584 \\
& 6 & 0.177 & 0.526 & -0.203 & 0.844 \\
& 8 & 0.126 & 0.562 & 0.222 & 0.807
\end{tabular}

$\begin{array}{cccccc} & 2 & 0.312 & 0.531 & -0.648 & 0.948 \\ & 4 & 0.328 & 0.999 & -0.045 & 0.999 \\ \text { Checklist } & 6 & 0.426 & 0.994 & 0.478 & 0.998 \\ & 8 & 0.416 & 0.999 & 0.663 & 0.999\end{array}$

$\begin{array}{cccccc} & 2 & 0.198 & 0.186 & -0.130 & 0.753 \\ & 4 & -0.066 & 0.605 & -0.088 & 0.806 \\ \text { Targeting } & 6 & -0.176 & 0.311 & 0.014 & 0.923 \\ & 8 & -0.117 & 0.414 & 0.127 & 0.300\end{array}$

Note: ${ }^{*}$ and ${ }^{* *}$ represents significance at the $1 \%$ and $10 \%$ level of confidence respectively; estimates corrected for autocorrelation and heteroskedasticity using Newey and West (1987). Estimation by instrumental variables with a constant, $i_{t}^{5 y e a r}, i_{t}^{\text {cash }}$ as instruments. 


\section{References}

[1] Alles, L. (1995), 'The Australian term structure as a predictor of real economic activity', Australian Economic Review, (4th quarter), 71-85.

[2] Bernanke, Ben S. (2006), 'Reflections on the Yield Curve and Monetary Policy', Speech to the Economic Club of New York, March 20.

[3] Bordo, Michael D and Joseph G. Haubrich (2004), 'The Yield Curve, Recessions, and the Credibility of the Monetary Regime: Long-Run Evidence, 1875-1997.' Working Paper 04-02. Federal Reserve Bank of Cleveland.

[4] Claus, Edda and Mardi Dungey (2006), 'Yield curve responses to monetary policy in the presence of asymmetric information', Working Paper, ANU Centre for Applied Macroeconomic Analysis, March.

[5] Ellingsen, T. and U. Söderström (2001), 'Monetary policy and market interest rates', American Economic Review, 91(5) 1594-1607.

[6] Fisher, C. and B. Felmingham (1998), 'The Australian yield curve as a leading indicator of consumption growth' Applied Financial Economics, 8, $627-35$.

[7] Ford, B. and K. Taylor (2005), Recent developments in Australian bond yields' Australian Treasury Economic Roundup, Spring, 111-120.

[8] Grenville, Stephen. (1997), 'The Evolution of Monetary Policy: From Money Targets to Inflation Targets.' http://www.rba.gov.au/PublicationsAndResearch/Conferences/1997/

Grenville.pdf.

[9] Hamilton, James D and Dong Heon Kim (2002), 'A Reexamination of the Predictability of Economic Activity Using the Yield Spread.' Journal of Money, Credit and Banking, 34(2), 340-360.

[10] Harvey, Campbell. R. (1988), 'The Real Term Structure and Consumption Growth.' Journal of Financial Economics, Vol 22. pp305-333. 
[11] Karfakis, Costas I. and Demetrios M. Moschos (1995), 'The Information Content of the Yield Curve in Australia', Journal of Macroeconomics, 17(1), 93-109.

[12] Karunaratne, N.D. (1999), 'The yield curve as a predictor of growth and recession in Australia', Discussion Paper 255, Department of Economics, University of Queensland, May.

[13] Lowe, P. (1992), 'The term structure of interest rates, real activity and inflation', Research Discussion Paper 9204, Reserve Bank of Australia, May.

[14] Macfarlane, Ian. J. (1998), 'Australian Monetary Policy in the Last Quarter of the Twentieth Century.' Shann Memorial Lecture, delivered at the University of Western Australia.

[15] Newey, Whitney and Kenneth West (1987), 'A Simple, Positive SemiDefinite, Heteroskedasticity and Autocorrelation Consistent Covariance Matrix.' Econometrica, 55, 703-708.

[16] Plosser, Charles. I and Geert. K. Rouwenhorst (1994), 'International Term Structures and Real Economic Growth.' Journal of Monetary Economics, $33,133-155$.

[17] Rudebusch, Glenn D., Brian P. Sack and Eric T. Swanson (2007), 'Macroeconomic Implications of Changes in the Term premium', Federal Reserve Bank of St Louis Review, July/August 241-270.

[18] Stock, J.H. and M.W. Watson (2003), 'Forecasting Output and Inflation: The Role of Asset Prices', Journal of Economic Literature, 41 (3), 788-829.

[19] Wright, Jonathan. H. (2006), 'The Yield Curve and Predicting Recessions.' Federal Reserve Board, Washington DC. 


\section{School of Economics and Finance Discussion Papers}

2007-01

2007-02

2007-03

2007-04

2007-05

2007-06

2007-07

2007-08

2007-09

2007-10

2006-01

2006-02

2006-03

2006-04

2006-05

2006-06

2006-07

2006-08

2006-09

2006-10

2006-11

2005-01

2005-02

2005-03

2005-04

2005-05

2005-06

2005-07

2005-08

2005-09

2005-10

2005-11

Dietary Changes, Calorie Intake and Undernourishment: A Comparative Study of India and Vietnam, Ranjan Ray

A Re-examination of the Real Interest Parity Condition Using Threshold Cointegration, Arusha Cooray

Teaching Aggregate Demand and Supply Models, Graeme Wells

Markets, Institutions and Sustainability, Ella Reeks

Bringing Competition to Urban Water Supply, Hugh Sibly and Richard Tooth

Changes in Indonesian Food Consumption Patterns and their Nutritional Implications, Elkana Ngwenya and

Ranjan Ray

The Term Spread and GDP Growth in Australia, Jacob Poke and Graeme Wells

Moving Towards the USDA Food Guide Pyramid Food: Evidence from Household Food Group Choice in Vietnam, Elkana Ngwenya

The Determinants of the Quantity-Quality Balance in Monopoly, Hugh Sibly

Rationing Recreational Access to Wilderness and Other Natural Areas, Hugh Sibly

Estimates of Technology and Convergence: Simulation Results, Graeme Wells and Thanasis Stengos

Dietary Pattern, Calorie Intake and Undernourishment: The Vietnamese Experience, Vinod Mishra and Ranjan Ray

Early Retirement in the Funding of Australian Retirement, Bruce Felmingham, Yong Hong Yan, Natalie Jackson and Maggie Walter

The Cyclical and Trend Behaviour of Australian Investment and Savings, Bruce Felmingham and

\section{Arusha Cooray}

Education and Child Labour: A Global Perspective, Ranjan Ray

A Regular Demand System with Commodity-Specific Demographic Effects, Paul Blacklow, Russell

Cooper, Roger Ham and Keith McLaren

\section{Fertility Choices of Australian Couples, Paul Blacklow}

Is there Gender Bias in the Household's time Allocation in a Developing Country? The Indian Experience, Pushkar Maitra and Ranjan Ray

\section{Examining Quality Distortion, Hugh Sibly}

The Day-of-the-Week (DoW) Efficiency of the S\&P/ASX20 Index and it's Component Stocks Nagaratnam Jeyasreedharan

Convergence to the Law of One Price: Evidence From Cross-Listed Chinese Stocks, Yong Hong Yan, Graeme Wells and Bruce Felmingham

Investment and Savings Cycles and Tests for Capital Market Integration, Arusha Cooray and Bruce Felmingham

The Efficiency of Emerging Stock Markets: Empirical Evidence from the South Asian Region, Arusha Cooray and Guneratne Wickremasinghe

Error-Correction Relationships Between High, Low and Consensus Prices, Nagaratnam Jeyasreedharan

Tests for RIP Among the G7 When Structural Breaks are Accommodated, Bruce Felmingham and Arusha Cooray

Alternative Approaches to Measuring Temporal Changes in Poverty with Application to India, Dipankor Coondoo, Amita Majumder, Geoffrey Lancaster and Ranjan Ray

Intertemporal Household Demographic Models for Cross Sectional Data, Paul Blacklow

Some Recent Evidences about the Global Integration of Chinese Share Markets, Yong Hong Yan and Bruce Felmingham

Managerial Objectives and Use Limits on Resource-Based Recreations, Hugh Sibly

The Feldstein-Horioka Model Re-Visted for African Countries, Arusha Cooray and Dipendra Sinha

Analysis of Changes in Food Consumption and their Implications for Food Security and Undernourishment: The Indian Experience in the 1900s, Ranjan Ray

Felmingham and Arusha Cooray

Copies of the above mentioned papers and a list of previous years' papers are available on request from the Discussion Paper Coordinator, School of Economics and Finance, University of Tasmania, Private Bag 85, Hobart, Tasmania 7001, Australia. Alternatively they can be downloaded from our home site at http://www.utas.edu.au/ecofin 